\title{
Hemostasis functions are associated with hemorrhagic transformation in non-atrial fibrillation patients: a case-control study
}

\author{
Hao-Ran Cheng ${ }^{1 \dagger}$, Yun-Bin Chen ${ }^{1 \dagger}$, Ya-Ying Zeng ${ }^{1 \dagger}$, Yi-Ting Ruan ${ }^{1}$, Cheng-Xiang Yuan', Qian-Qian Cheng ${ }^{2}$,
} Hui-Jun Chen', Xiao-Qian Luan', Gui-Qian Huang ${ }^{1 *}$ and Jin-Cai He ${ }^{1 *}$ (D)

\begin{abstract}
Background: Hemorrhagic transformation (HT) is a serious neurological complication of acute ischemic stroke (AIS) after revascularization. The majority of AIS patients do not have atrial fibrillation (AF) which could also develop into HT. In this study, we aimed to explore whether hemostasis parameters are risk factors of HT in non-AF patients.

Methods: We consecutively enrolled 285 AIS patients with HT. Meanwhile, age- and sex-matched 285 AIS patients without HT were included. The diagnosis of HT was determined by brain CT or MRI during hospitalization. All patients were divided into two subgroups based on the presence of AF and explore the differences between the two subgroups. Blood samples were obtained within $24 \mathrm{~h}$ of admission, and all patients were evenly classified into three tertiles according to platelet counts (PLT) levels.

Results: In this study, we found the first PLT tertile $(O R=3.509,95 \% \mathrm{Cl}=1.268-9.711, P=0.016)$ was independently associated with HT in non-AF patients, taking the third tertile as a reference. Meanwhile, we also found mean platelet volume (MPV) $(\mathrm{OR}=0.605,95 \% \mathrm{Cl}=0.455-0.805, P=0.001)$ and fibrinogen ( $\mathrm{FIB})(\mathrm{OR}=1.928,95 \% \mathrm{Cl}=$ 1.346-2.760, $P<0.001$ ) were significantly associated with HT in non-AF patients. But in AF patients, hemostasis parameters showed no significant difference. Meanwhile, we found the MPV $(\mathrm{OR}=1.314,95 \% \mathrm{Cl}=1.032-1.675$, $P=0.027)$ and $\mathrm{FIB}(\mathrm{OR}=1.298,95 \% \mathrm{Cl}=1.047-1.610, P=0.018)$ were significantly associated with long-term outcomes in non-AF HT patients.

Conclusions: Low PLT, low MPV, and high FIB levels were independently associated with HT in non-AF patients. Additionally, MPV and FIB levels were significantly associated with unfavorable long-term outcomes in non-AF HT patients. Our study showed that hemostasis functions at admission may be beneficial for clinicians to recognize patients with a high risk of $\mathrm{HT}$ at an early stage and improve unfavorable long-term outcomes in non-AF patients.
\end{abstract}

Keywords: Hemorrhagic transformation, Hemostasis function, Atrial fibrillation, Acute ischemic stroke

\footnotetext{
*Correspondence: huangguiqian123@126.com; hjc@wmu.edu.cn

${ }^{\dagger}$ Hao-Ran Cheng, Yun-Bin Chen and Ya-Ying Zeng are co-first authors.

'Department of Neurology, The First Affiliated Hospital of Wenzhou Medical University, Wenzhou 325000, Zhejiang, China

Full list of author information is available at the end of the article
}

(C) The Author(s). 2021 Open Access This article is licensed under a Creative Commons Attribution 4.0 International License, which permits use, sharing, adaptation, distribution and reproduction in any medium or format, as long as you give appropriate credit to the original author(s) and the source, provide a link to the Creative Commons licence, and indicate if changes were made. The images or other third party material in this article are included in the article's Creative Commons licence, unless indicated otherwise in a credit line to the material. If material is not included in the article's Creative Commons licence and your intended use is not permitted by statutory regulation or exceeds the permitted use, you will need to obtain permission directly from the copyright holder. To view a copy of this licence, visit http://creativecommons.org/licenses/by/4.0/ The Creative Commons Public Domain Dedication waiver (http://creativecommons.org/publicdomain/zero/1.0/) applies to the data made available in this article, unless otherwise stated in a credit line to the data. 


\section{Background}

Hemorrhagic transformation (HT), one of the most common neurological complications after acute ischemic stroke (AIS), is associated with early mortality and poor outcomes after stroke [1-6]. Currently, many risk factors related to HT have been identified including old age, the severity of a stroke, dyslipidemia, hyperglycemia, hemoglobin A1c, atrial fibrillation (AF), and thrombolytic therapy [7-9].

It has been reported that AF and some medication used for its treatment such as Warfarin could cause HT [10-13]. In 2019, Jiao et al. found that AF independently correlated with HT and was a risk factor of HT [8]. In a prospective trial of 101 AIS patients, Tu et al. found that AF patients had significant hypoperfusion that may damage vascular integrity leading to a more frequent HT [12]. Meanwhile, Altavilla et al. found that patients with AF who received low-molecular-weight heparin have a higher risk of HT than non-bridged patients [14]. Besides, an animal experiment found that the incidence of HT in rats treated with Warfarin was increased [13].

However, HT has been underexplored in non-AF patients; the majority of AIS patients are non-AF patients $[15,16]$ and they could also develop HT. Meanwhile, AF and medication for AF would influence hemostasis functions $[17,18]$. Thus, the risk factors of non-AF patients to develop HT after AIS need to be further explored, especially hemostasis functions.

In this research, we mainly explored the association between hemostasis functions and HT in patients with $\mathrm{AF}$ and without AF and aimed to identify hemostatic parameters as risk factors in non-AF HT patients.

\section{Methods}

\section{Subjects}

This was a retrospective study of patients with and without hemorrhagic transformation after stroke. The study protocol obtained the approval of the Ethics Committee of the First Affiliated Hospital of Wenzhou Medical University. We didn't have informed consent for it was a retrospective study and the patient profile was anonymous. The cohort was made up of the First Affiliated Hospital of Wenzhou Medical University's clinical database of HT; the same amounts of stroke patients without HT from our stroke center were matched by age and sex using the same inclusion and exclusion criteria. All patients who were diagnosed with HT in the First Affiliated Hospital of Wenzhou Medical University were included in this study from December 2013 to December 2015. The inclusion criteria were as follows: (1) age between 18 and 99 years; (2) patient was included within 7 days of stroke; (3) the diagnosis of stroke was confirmed by computerized tomography (CT) or magnetic resonance imaging (MRI) at the time of admission. The exclusion criteria were as follows: (1) hemorrhagic stroke or transient ischemic attack (TIA); (2) patient received intravenous thrombolytic therapy; (3) patients with any severe liver or kidney dysfunction; (4) patients failed to receive a repeat CT/MRI scan; (5) patients' medical record was incomplete.

\section{Diagnosis of HT}

All patients received a brain CT scan or MRI including diffusion-weighted imaging (DWI) and T2-weighted gradient-echo within $24 \mathrm{~h}$ after stroke onset. HT was diagnosed in a subsequent CT/MRI performed $7 \pm 2$ days after stroke onset or whenever a worsening clinical condition. Two neurologists evaluated the CT/MRI scans independently and diagnosed HT, who were blinded to the results of clinical and laboratory measurements. In this study, HT was categorized radiologically as follows according to the recommendations of the European Cooperative Acute Stroke Study [19, 20]. Hemorrhagic infarct types 1 and 2 were defined as punctate petechiae along the margins of the infarction (HI-1); and more confluent petechiae within the infarcted area, but no space-occupying effect (HI-2). Parenchymal hematoma types 1 and 2 and were defined as hematoma with slight space-occupying effect ( $\leq 30 \%$ infarcted area) (PH-1); and hematoma with significant space-occupying effect (> 30\% infarcted area) or intraparenchymal hemorrhage outside the infarcted area (PH-2).

\section{Data collection}

Patients' demographic data and personal hobbies included gender, age, current smoking, and drinking. Past medical history included the previous history of stroke, hypertension, diabetes mellitus, coronary artery disease (CAD), atrial fibrillation, and hyperlipidemia. Meanwhile, the National Institutes of Health Stroke Scale (NIHSS) was used to evaluate the severity of stroke within $24 \mathrm{~h}$ after admission. All patients identified the stroke subtypes according to the TOAST criteria [21]. Blood samples and blood pressure were obtained within $24 \mathrm{~h}$ of hospital admission and sent blood samples for tests as soon as possible. Laboratory tests included leukocyte counts, erythrocyte counts, platelet counts (PLT), mean platelet volume (MPV), prothrombin time (PT), international normalized ratio (INR), and fibrinogen (FIB). Also, drug applications in the hospital including anticoagulant, antiplatelet, and lipid-lowering drugs were collected and documented. All patients were evenly classified into three tertiles according to the PLT levels (tertile 1, <175; tertile 2, 175-222; and tertile 3, > 222).

In December 2019, HT patients were followed up by telephone to collect their up-to-date functional conditions. We used the modified Rankin Scale (mRS) to assess long-term functional outcomes, and an unfavorable 
functional outcome was defined as an mRS score of $\geq 2$ [22-25]. The primary outcome was defined as mRS.

\section{Statistical analyses}

Statistical descriptions of continuous variables were mean \pm SD or medians (quartiles), while categorical variables were percentages. The comparison of continuous variables used the Student's t-test or Mann-Whitney test, while categorical variables used the Chi-square test or Fisher's exact test. The comparison of the differences between three PLT tertiles in continuous variables used the Kruskal-Wallis test or one-way analysis of variance (ANOVA), while categorical variables used the Pearson's chi-square or Fisher's exact tests. The same way used in the comparison of the differences between the other three groups. Multiple logistic regression analysis was performed to identify significant independent related factors of HT and adjust potential confounding factors. Cox proportional hazards model was performed to identify the significant independent related factors of unfavorable long-term outcomes in non-AF HT patients and adjust potential confounding factors. All statistical analyses used IBM SPSS Statistics for Windows, Version: 19.0.0 (Chicago, IL). Two-tailed $P$-values $<0.05$ were considered statistically significant.

\section{Results}

\section{Baseline characteristics of patients stratified by HT}

In this study, 285 AIS patients with HT and age- and sex-matched 285 AIS patients without HT were included. The baseline demographic, clinical, and laboratory characteristics of the study patients were presented in Table 1 . The mean age of the enrolled patients was $68.9 \pm 12.4$ years. $388(68.1 \%)$ patients were male and 182 (31.9\%) were female. Also, 137 (24.0\%) patients had a history of AF. As for the etiological factors of stroke, among all the enrolled patients, 405 (75.6\%) patients were because of atherosclerosis, 109 (20.3\%) patients were because of cardioembolism, 4 (0.7\%) patients were because of small vessel occlusion and 18 (3.3\%) patients were because of other causes. Separately, the proportion of cardioembolism among the HT patients was more than the non-HT patients $(P<0.001$, Table 1$)$. As shown in Table 1, patients with HT had lower baseline systolic blood pressure (SBP), PLT, and MPV; higher leukocyte counts, PT, INR, and FIB compared with patients without HT. They also had higher NIHSS scores at admission. AF was more frequently found in patients with HT and the proportion of AF among HT and non-HT patients was 108 (37.9\%) and 29 (10.2\%) respectively. As for the anticoagulant and antiplatelet therapy, non-HT patients had a higher proportion of antiplatelet therapy $(P<0.001$, Table 1$)$ than HT patients, and HT patients had a higher proportion of anticoagulant therapy $(P<0.001$, Table 1$)$ than non-HT patients. Separately, non-HT patients also had a higher proportion of antiplatelet therapy than HT patients among the AF group and non-AF group $(P=0.044$ and $P<$ 0.001 , respectively; Supplementary Table 1. There was no significant difference in anticoagulant therapy among the AF group. Non-HT patients had a higher proportion of double antiplatelet therapy than HT patients $(P=0.025$, Table 1$)$. In non-AF patients, 237 (92.6\%) non-HT patients and 115 (65.0\%) HT patients received antiplatelet therapy; 56 (21.9\%) non-HT patients and 25 (14.1\%) HT patients received double antiplatelet therapy (Supplementary Table 1). And the antiplatelet agents included Aspirin and Clopidogrel. Besides, patients with HT were more likely to smoke and drink.

According to the radiological features, HT patients were classified to 61 (21.4\%) HI-1, 86 (30.2\%) HI-2, 69 (24.2\%) PH-1 and 69 (24.2\%) PH-2. In the Supplemental Table 2, PH patients had lower PLT, lower FIB and higher MPV than HI patients.

\section{Baseline characteristics of AIS patients according to PLT tertiles}

Demographic and laboratory variables according to PLT tertiles were presented in Table 2. The incidence of HT was significantly higher in the first PLT tertile than the second and third MLR tertiles (63.7\% versus 42.8 and $43.2 \%$, respectively; $P<0.001$ ). As shown in Table 2 , patients with lower PLT levels were more likely to be drinkers and CAD patients; had lower leukocyte counts and FIB levels, and had higher MPV, PT, and INR levels; and were more likely to receive anticoagulant therapy, less likely to receive antiplatelet therapy.

\section{Characteristics of patients with HT in subcategorized groups of AF}

The incidence of HT was higher in the AF subgroup than in non-AF $(78.8 \%$ vs. $40.9 \%, P<0.001)$. In the subgroup of non-AF patients, the significant parameters between HT and non-HT (Supplemental Table 3) were generally consistent with the parameters in Table 1 . But in AF patients, patients with HT had higher levels of leukocyte counts, lower SBP; higher NIHSS scores at admission; and more smokers and drinkers. In AF patients, there were no significant differences in hemostasis parameters among HT and non-HT patients.

\section{Association between hemostasis parameters and HT}

The occurrence of HT was used as a dependent variable and the third PLT tertile was used as a reference in the multivariate regression in all patients. After adjusting for confounding and risk factors, multivariate regression analysis showed that the first PLT tertile $(\mathrm{OR}=3.517$, 
Table 1 Baseline characteristics of AIS patients without HT and with HT

\begin{tabular}{|c|c|c|c|c|}
\hline Variables & Total $(n=570)$ & Non-HT $(n=285)$ & HT $(n=285)$ & $P$-value \\
\hline \multicolumn{5}{|l|}{ Demographic characteristics } \\
\hline Age (years) & $68.9 \pm 12.4$ & $68.9 \pm 12.3$ & $68.9 \pm 12.6$ & 0.970 \\
\hline Male, n (\%) & $388(68.1 \%)$ & $191(67.0 \%)$ & 197 (69.1\%) & 0.590 \\
\hline Baseline SBP (mmHg) & $153.3 \pm 23.1$ & $158.0 \pm 23.0$ & $148.6 \pm 22.3$ & $<0.001$ \\
\hline Baseline DBP (mmHg) & $82.3 \pm 13.8$ & $82.1 \pm 13.3$ & $82.5 \pm 14.3$ & 0.732 \\
\hline NIHSS on admission, median (IQR) & $5.0(2.0-10.0)$ & $3.0(1.0-5.0)$ & $9.0(5.0-13.0)$ & $<0.001$ \\
\hline CTA, n (\%) & $64(11.2 \%)$ & $30(10.5 \%)$ & $34(11.9 \%)$ & 0.616 \\
\hline \multicolumn{5}{|l|}{ Vascular risk factors, n (\%) } \\
\hline Current smoking & $210(37.1 \%)$ & $118(41.5 \%)$ & $92(32.6 \%)$ & 0.028 \\
\hline Current drinking & $228(40.4 \%)$ & $141(49.8 \%)$ & 87 (30.9\%) & $<0.001$ \\
\hline Previous Stroke & $72(12.6 \%)$ & $31(10.9 \%)$ & $41(14.4 \%)$ & 0.207 \\
\hline Hypertension & $376(66.0 \%)$ & $197(69.1 \%)$ & $179(62.8 \%)$ & 0.112 \\
\hline Diabetes & 149 (26.1\%) & $80(28.1 \%)$ & $69(24.2 \%)$ & 0.294 \\
\hline CAD & $47(8.3 \%)$ & $15(5.3 \%)$ & $32(11.3 \%)$ & 0.010 \\
\hline Dyslipidemia & $37(6.5 \%)$ & $17(6.0 \%)$ & $20(7.0 \%)$ & 0.610 \\
\hline $\mathrm{AF}$ & $137(24.0 \%)$ & $29(10.2 \%)$ & $108(37.9 \%)$ & $<0.001$ \\
\hline \multicolumn{5}{|l|}{ Hematological variables } \\
\hline Leukocyte counts $\left(\times 10^{9} / L\right)$ & $7.7 \pm 2.8$ & $6.8 \pm 1.9$ & $8.5 \pm 3.3$ & $<0.001$ \\
\hline Erythrocyte counts $\left(\times 10^{9} / L\right)$ & $4.4 \pm 0.6$ & $4.4 \pm 0.6$ & $4.4 \pm 0.6$ & 0.836 \\
\hline $\mathrm{PLT}\left(\times 10^{9} / \mathrm{L}\right)$, median (IQR) & $197.0(162.0-235.0)$ & $205.0(175.0-238.5)$ & $187.0(148.5-231.0)$ & $<0.001$ \\
\hline MPV (fl) & $11.0 \pm 1.4$ & $11.2 \pm 1.2$ & $10.8 \pm 1.4$ & 0.011 \\
\hline PT (s) & $13.7 \pm 1.0$ & $13.5 \pm 1.0$ & $13.9 \pm 1.0$ & $<0.001$ \\
\hline INR & $1.1 \pm 0.1$ & $1.0 \pm 0.1$ & $1.1 \pm 0.1$ & $<0.001$ \\
\hline $\mathrm{FIB}(\mathrm{g} / \mathrm{L})$ & $3.8 \pm 1.6$ & $3.5 \pm 1.0$ & $4.1 \pm 2.0$ & $<0.001$ \\
\hline Stroke etiology, n (\%) & & & & $<0.001$ \\
\hline Atherosclerosis & $405(75.6 \%)$ & $214(84.9 \%)$ & $191(67.3 \%)$ & \\
\hline Cardioembolism & 109 (20.3\%) & $20(7.9 \%)$ & $89(31.3 \%)$ & \\
\hline Small vessel occlusion & $4(0.7 \%)$ & $3(1.2 \%)$ & $1(0.4 \%)$ & \\
\hline Other causes & $18(3.3 \%)$ & $15(6.0 \%)$ & $3(1.1 \%)$ & \\
\hline \multicolumn{5}{|l|}{ Treatment, n (\%) } \\
\hline Anticoagulant therapy & 114 (20\%) & $28(9.8 \%)$ & $86(30.2 \%)$ & $<0.001$ \\
\hline Antiplatelet therapy & 419 (73.5\%) & $256(89.8 \%)$ & $163(57.2 \%)$ & $<0.001$ \\
\hline Aspirin & $201(35.3 \%)$ & $120(42.1 \%)$ & $81(28.4 \%)$ & 0.001 \\
\hline Clopidogrel & $122(21.4 \%)$ & $78(27.4 \%)$ & $44(15.4 \%)$ & $<0.001$ \\
\hline Double antiplatelet therapy & $96(16.8 \%)$ & $58(20.4 \%)$ & $38(13.3 \%)$ & 0.025 \\
\hline
\end{tabular}

Abbreviations: HT, hemorrhagic transformation; SBP, systolic blood pressure; DBP, diastolic blood pressure; NIHSS, National Institute of Health Stroke Scale; CTA, computered tomograhy angiography; CAD, coronary artery disease; AF, atrial fibrillation; PLT, platelet counts; MPV, mean platelet volume; PT, prothrombin time; INR, International Normalized Ratio; FIB, fibrinogen

95\%CI $=1.526-8.106, P=0.003$; Table 3 ) was independently associated with $\mathrm{HT}$ in all patients. Meanwhile, $\mathrm{MPV}(\mathrm{OR}=0.698,95 \% \mathrm{CI}=0.557-0.875, P=0.002$; Table 3$)$ and FIB (OR $=1.613,95 \% \mathrm{CI}=1.199-2.169, \mathrm{P}$ $=0.002$; Table 3 ) were also significantly associated with $\mathrm{HT}$ in all patients.

Considering the potential relationship between AF and hemostasis function, we divided all patients into AF and
non-AF subgroups. In non-AF subgroup, we found the first PLT tertile $(\mathrm{OR}=3.509,95 \% \mathrm{CI}=1.268-9.711, P=$ 0.016; Table 4), MPV (OR $=0.605,95 \% \mathrm{CI}=0.455-0.805$, $P=0.001$; Table 4$)$ and FIB (OR $=1.928,95 \%$ CI $=1.346-$ 2.760, $P<0.001$; Table 4) were significantly associated with $\mathrm{HT}$ after adjusting for confounding factors. In the AF subgroup, hemostasis parameters showed no significant association with HT. 
Table 2 Baseline characteristics of AIS patients according to PLT tertiles

\begin{tabular}{|c|c|c|c|c|}
\hline \multirow[t]{2}{*}{ Variables } & \multicolumn{4}{|l|}{ PLT tertiles } \\
\hline & Tertile1 $(n=193)$ & Tertile2 $(n=187)$ & Tertile3 $(n=190)$ & $P$-value \\
\hline PLT (×109/L) & $<175$ & $175-222$ & $>222$ & \\
\hline HT, n (\%) & $123(63.7 \%)$ & $80(42.8 \%)$ & $82(43.2 \%)$ & $<0.001$ \\
\hline \multicolumn{5}{|l|}{ Demographic characteristics } \\
\hline Age (years) & $70.2 \pm 11.6$ & $68.9 \pm 12.7$ & $67.5 \pm 12.8$ & 0.970 \\
\hline Male, n (\%) & 147 (76.2\%) & $130(69.5 \%)$ & $111(58.4 \%)$ & 0.590 \\
\hline Baseline SBP $(\mathrm{mmHg})$ & $150.0 \pm 22.2$ & $157.8 \pm 21.8$ & $152.3 \pm 24.5$ & $<0.001$ \\
\hline Baseline DBP (mmHg) & $81.6 \pm 14.0$ & $83.2 \pm 14.2$ & $82.2 \pm 13.2$ & 0.732 \\
\hline NIHSS on admission, median (IQR) & $5.0(3.0-11.0)$ & $4.5(2.0-9.0)$ & $5.0(2.0-9.0)$ & 0.028 \\
\hline CTA, n (\%) & $16(8.3 \%)$ & $26(13.9 \%)$ & $22(11.6 \%)$ & 0.218 \\
\hline \multicolumn{5}{|l|}{ Vascular risk factors, n (\%) } \\
\hline Current smoking & $64(33.2 \%)$ & $64(34.2 \%)$ & $82(43.2 \%)$ & 0.028 \\
\hline Current drinking & $80(41.5 \%)$ & $74(39.6 \%)$ & $74(38.9 \%)$ & $<0.001$ \\
\hline Previous Stroke & $26(13.5 \%)$ & $20(10.7 \%)$ & $26(13.7 \%)$ & 0.207 \\
\hline Hypertension & 115 (59.6\%) & $132(70.6 \%)$ & $129(67.9 \%)$ & 0.112 \\
\hline Diabetes & $45(23.3 \%)$ & $56(29.9 \%)$ & $48(25.3 \%)$ & 0.294 \\
\hline CAD & $23(11.9 \%)$ & $14(7.5 \%)$ & $10(5.3 \%)$ & 0.010 \\
\hline Dyslipidemia & $12(6.2 \%)$ & $13(7.0 \%)$ & $12(6.3 \%)$ & 0.610 \\
\hline $\mathrm{AF}$ & $63(32.6 \%)$ & $41(21.9 \%)$ & $33(17.4 \%)$ & $<0.001$ \\
\hline \multicolumn{5}{|l|}{ Hematological variables } \\
\hline Leukocyte counts $\left(\times 10^{9} / L\right)$ & $7.4 \pm 2.8$ & $7.8 \pm 3.0$ & $7.8 \pm 2.6$ & $<0.001$ \\
\hline Erythrocyte counts $\left(\times 10^{9} / \mathrm{L}\right)$ & $4.4 \pm 0.6$ & $4.5 \pm 0.6$ & $4.4 \pm 0.5$ & 0.836 \\
\hline MPV (fl) & $11.3 \pm 1.5$ & $10.9 \pm 1.4$ & $10.6 \pm 1.2$ & 0.007 \\
\hline $\mathrm{PT}(\mathrm{s})$ & $14.0 \pm 1.1$ & $13.6 \pm 1.0$ & $13.5 \pm 1.0$ & $<0.001$ \\
\hline INR & $1.1 \pm 0.1$ & $1.0 \pm 0.1$ & $1.0 \pm 0.1$ & $<0.001$ \\
\hline $\mathrm{FIB}(\mathrm{g} / \mathrm{L})$ & $3.7 \pm 1.2$ & $3.7 \pm 1.1$ & $4.0 \pm 2.3$ & $<0.001$ \\
\hline Stroke etiology, n (\%) & & & & $<0.001$ \\
\hline Atherosclerosis & $126(68.4 \%)$ & $137(73.3 \%)$ & $142(74.7 \%)$ & \\
\hline Cardioembolism & $51(26.4 \%)$ & $29(15.5 \%)$ & $29(15.3 \%)$ & \\
\hline Small vessel occlusion & $2(1.0 \%)$ & $1(0.5 \%)$ & $1(0.5 \%)$ & \\
\hline Other causes & $6(3.1 \%)$ & $8(4.2 \%)$ & $4(2.1 \%)$ & \\
\hline \multicolumn{5}{|l|}{ Treatment, n (\%) } \\
\hline Anticoagulant therapy & $61(31.6 \%)$ & $26(13.9 \%)$ & $27(14.2 \%)$ & $<0.001$ \\
\hline Antiplatelet therapy & 122 (63.2\%) & $150(80.2 \%)$ & $142(74.7 \%)$ & $<0.001$ \\
\hline
\end{tabular}

Abbreviations: PLT, platelet counts; HT, hemorrhagic transformation; SBP, systolic blood pressure; DBP, diastolic blood pressure; NIHSS, National Institute of Health Stroke Scale; $C T A$, computered tomograhy angiography; CAD, coronary artery disease; $A F$, atrial fibrillation; MPV, mean platelet volume; PT, prothrombin time; INR, International Normalized Ratio; FIB, fibrinogen

After adjusting for confounding factors, we found $\mathrm{MPV}(\mathrm{OR}=0.744,95 \% \mathrm{CI}=0.594-0.931, P=0.010$; Supplemental Table 3) were significantly associated with HI. Meanwhile, the first PLT tertile (OR $=3.719,95 \% \mathrm{CI}$ $=1.551-8.916, P=0.003$; Supplemental Table 3) were significantly associated with $\mathrm{PH}$ after adjusting for confounding factors.
Results of long-term functional outcomes after HT

Of 285 HT patients, 143 (50.2\%) were available for follow-up in December 2019 through phone calls and the median follow-up time was 4.75 years (IQR 2.826.14). Among 143 follow-up patients, 85 were non-AF patients. In the long term, 58 (68.2\%) of the non-AF HT patients had unfavorable functional outcomes $(\mathrm{mRS} \geq 2)$. 
Table 3 Multivariate logistic regression analysis of predictive factors for HT in all patients

\begin{tabular}{|c|c|c|c|c|c|c|}
\hline & \multicolumn{2}{|l|}{ Model 1} & \multicolumn{2}{|l|}{ Model 2} & \multicolumn{2}{|l|}{ Model 3} \\
\hline & adjust OR(95\%Cl) & $P$-value & adjust $\mathrm{OR}(95 \% \mathrm{Cl})$ & $P$-value & adjust OR(95\%Cl) & $P$-value \\
\hline \multicolumn{7}{|l|}{ PLT } \\
\hline $\mathrm{T} 1$ & $2.002(1.160-3.454)$ & 0.013 & $3.887(1.762-8.575)$ & 0.001 & $3.517(1.526-8.106)$ & 0.003 \\
\hline $\mathrm{T} 2$ & $1.055(0.617-1.803)$ & 0.845 & $1.425(0.710-2.861)$ & 0.319 & $1.525(0.738-3.149)$ & 0.254 \\
\hline T3 & Ref & & Ref & & Ref & \\
\hline MPV & - & - & $0.714(0.573-0.890)$ & 0.003 & $0.698(0.557-0.875)$ & 0.002 \\
\hline PT & - & - & $3.624(1.015-12.939)$ & 0.047 & $3.599(0.941-13.767)$ & 0.061 \\
\hline INR & - & - & $0.904(0.796-1.027)$ & 0.121 & $0.904(0.791-1.035)$ & 0.143 \\
\hline FIB & - & - & $1.570(1.191-2.069)$ & 0.001 & $1.613(1.199-2.169)$ & 0.002 \\
\hline
\end{tabular}

Notes: Model 1: adjusted sex, age, smoking, drinking, CAD, AF, baseline SBP, NIHSS on admission; Model 2: adjusted for covariates from Model 1 and further adjusted for MPV, PT, INR, FIB and leukocyte counts; Model 3: adjusted for covariates from Model 2 and further adjusted for anticoagulant therapy and antiplatelet therapy

Abbreviations: $\mathrm{Cl}$, confidence interval; OR, odds ratio; $\mathrm{HT}$, hemorrhagic transformation; PLT, platelet counts; MPV, mean platelet volume; PT, prothrombin time; INR, International Normalized Ratio; FIB, fibrinogen

After adjusting for confounding factors, Cox proportional hazards regression analysis showed that MPV (OR $=1.314,95 \% \mathrm{CI}=1.032-1.675, P=0.027$; Table 5) and FIB $(\mathrm{OR}=1.298,95 \% \mathrm{CI}=1.047-1.610, P=0.018$; Table $5)$ was independently and significantly associated with long-term outcomes in non-AF HT patients.

\section{Discussion}

To the best of our knowledge, this is the first study to explore the association of hemostasis parameters and HT in non-AF patients; and to explore the effect of hemostasis parameters on long-term outcomes after HT in non-AF patients. Our present study showed that three hemostasis parameters including low PLT, low MPV, and high FIB were significant and dependent risk factors with HT in non-AF patients, instead of AF patients. Furthermore, we found that MPV and FIB levels were independently and significantly associated with unfavorable long-term functional outcomes in non-AF HT patients.

The etiological factors of stroke include atherosclerosis, cardioembolism, small vessel occlusion, and other causes. In this study, atherosclerosis was the most common cause of stroke among all the patients, which was consistent with previous studies. Atherosclerosis has been proved to be a major pathophysiological finding associated with a large proportion of ischemic stroke [26]. As for the HT patients, the proportion of cardioembolism was more than the non-HT group, which was also consistent with previous studies. Cardio embolism has been proved to be an independent risk factor for HT [27]. Consistent with many studies, we identified that AF was a reliable risk factor of $\mathrm{HT}$, and the incidence of HT among AF patients was higher than non-AF patients [7, $8,28,29]$. Considering the complex interaction between AF and HT [30], we did a subgroup analysis of our patients to explore the association between hemostasis functions and HT. Considering the complex interaction between AF and HT, we did a subgroup analysis to explore the association between coagulation functions and HT. We found none of the coagulation parameters was associated with HT among AF patients. However, there were very few studies on this topic, so we made some hypotheses based on our findings. The possible reasons are as follows. First, the proportion of antiplatelet therapy among AF patients was lower than non-AF. Thus, it may have little effect on platelet function and platelet count, which could not predict the prevalence of HT. Second, due to the high proportion and prolonged use of anticoagulants before admission among AF patients, coagulation functions of $\mathrm{AF}$ patients may worse than non-AF patients. Indeed, in our study, coagulation functions such as the levels of PT $(P<0.001)$, FIB $(P=$ $0.003)$ and INR $(\mathrm{P}<0.001)$ among AF patients were higher than non-AF. However, for AF patients, there was no difference in the proportion of anticoagulant therapy between HT and non-HT groups. Thus, there was no difference in the coagulation parameters between HT and non-HT groups, which could not predict the prevalence of HT.

However, our study suggested that PLT, MPV, and FIB were associated with HT significantly in non-AF patients. PLT is a key factor in the hemostasis process. According to clinical guidelines from the American Heart Association/American Stroke Association published in 2018, low PLT levels $(<100,000$ counts/ $\mu$ l) would increase the risk of HT [31] and do not recommend these patients to receive reperfusion therapies. Several studies also pointed out that PLT was associated with the occurrence of HT [8, 32]. Furthermore, a previous study identified that lower coated-platelets counts increased the likelihood of early HT in patients with non-lacunar ischemic stroke [33]. Platelet-endothelial interactions could maintain the structural integrity of blood vessels when a stroke occurs [34]. The patients with low PLT 


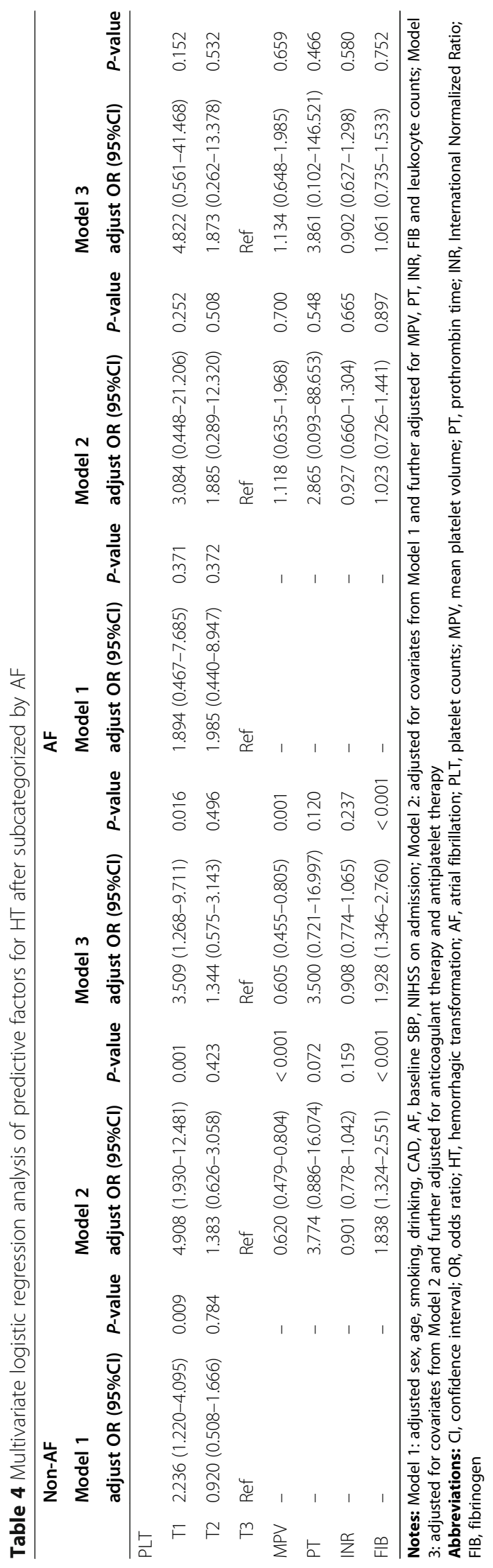


Table 5 Cox proportional hazards model of predictive factors for long-term outcome in non-AF HT patients

\begin{tabular}{llll}
\hline & HR & $\mathbf{9 5 \%} \mathbf{C l}$ & $\boldsymbol{P}$-value \\
\hline Sex & 0.618 & $0.304-1.258$ & 0.184 \\
Age & 1.020 & $0.985-1.057$ & 0.256 \\
NIHSS on admission & 1.065 & $0.989-1.146$ & 0.094 \\
Hypertension & 0.810 & $0.410-1.602$ & 0.545 \\
Diabetes & 2.706 & $1.170-6.254$ & 0.020 \\
CAD & 0.977 & $0.421-2.267$ & 0.956 \\
PLT & & & \\
$\quad$ T1 & 0.674 & $0.317-1.433$ & 0.306 \\
T2 & 1.399 & $0.632-3.098$ & 0.408 \\
$\quad$ T3 & Ref & & \\
MPV & 1.314 & $1.032-1.675$ & 0.027 \\
FIB & 1.298 & $1.047-1.610$ & 0.018 \\
Anticoagulant therapy & 0.875 & $0.427-1.794$ & 0.716 \\
Antiplatelet therapy & 0.838 & $0.429-1.636$ & 0.604 \\
\hline
\end{tabular}

NOTE. $\mathrm{Cl}$, confidence interval; $\mathrm{HR}$, hazard ratio; $\mathrm{AF}$, atrial fibrillation; $\mathrm{HT}$, hemorrhagic transformation; NIHSS, National Institute of Health Stroke Scale; CAD, coronary artery disease; PLT, platelet counts; MPV, mean platelet volume; FIB, fibrinogen

levels are weak in maintaining the blood vessels' integrity and are more likely to develop HT after AIS. SalasPerdomo et al. found in the experiment that using an anti-platelet serum in mice would lead to larger intraparenchymal hematomas after stroke [35], thus stressed the vital hemostatic function of platelets in AIS. This may because those platelets can physically cover the damaged vascular endothelium or release protective factors to protect the endothelial barrier function. These all indicated the importance of PLT in HT.

MPV describes the sizes of PLT, which is a marker of PLT activity and influences bleeding [36, 37]. In our study, MPV among HT patients was lower than non-HT. Besides, logistic regression analysis showed low MPV was a risk factor of HT. Early study found that larger PLT had more granules and would produce more vascular activity as well as pre-clotting factors, which may raise the hemostatic efficiency $[37,38]$. A retrospective study suggested that baseline MPV was associated with unfavorable stroke outcomes but its relationship with HT was still uncertain [39].

Previous studies briefly mentioned the relationship between FIB and HT [32, 40, 41]. And we found that higher FIB may be associated with a higher incidence of HT among AIS patients, which is congruent with some reports [40, 41]. However, Wang et al. found that FIB < $1.50 \mathrm{~g} / \mathrm{L}$ was a risk factor for HT [32]. We hypothesize that high levels of FIB may be associated with HT by participating in the inflammatory process. When HT occurs, endothelial dysfunction of capillaries would further lead to abnormal blood-brain barrier permeability within the infarcted area [42]. The dysfunction of the bloodbrain barrier in the infarcted area was proved to be the main cause of HT. Meanwhile, a review proposed that FIB was a ligand of cell surface receptors and this could promote the intercellular adhesion between inflammatory cells and endothelial [43]. In another study, an antiinflammatory thrombolytic drug called SMTP-7 could decrease the incidence of HT, which suggested the relationship between HT and inflammation [44]. Thus, the relationship between FIB and HT remains unknown and this needs to be further investigated.

In our study, we found that hemostasis functions were associated with unfavorable long-term outcomes in nonAF HT patients. Its exact mechanism remains unknown; however, the mechanism by which hemostasis function is related to unfavorable outcomes in intracerebral hemorrhage $(\mathrm{ICH})$ is unclear. Unfavorable outcomes after hemorrhage were reported to be conducted by the inflammatory effects of intraparenchymal blood [45]. Recently, Krenzlin $\mathrm{H}$ et al. found that the activated cerebral thrombin system was related to poor outcomes after $\mathrm{ICH}$ in mice. They suspected that the activated cerebral thrombin system may contribute to secondary brain damage [46]. Meanwhile, a previous study suggested that hemostasis function may influence neurovascular injury and neuroprotection [47].

Our study has some limitations. First, this was a singlecenter and retrospective study and we did not have the regular follow-up records such as $1,3,5$ years. So it is necessary to conduct multi-center, prospective studies to establish causality and provide detailed long-term prognostic information. Second, our study did not discuss the association between different subtypes of HT (hemorrhagic infarction or parenchymal hematoma) and hemostasis functions. In a further study, we could explore the association between the severity of HT and hemostasis functions. Third, owing to the infarction size was not documented, the associations between infarction size and HT were not described in detail. Fourth, our study did not collect the record of endovascular thrombectomy.

\section{Conclusions}

In summary, we found that three hemostasis parameters including low PLT, low MPV, and high FIB were risk factors among the non-AF patients, while these parameters were not associated with $\mathrm{HT}$ in AF patients. Meanwhile, MPV and FIB levels were independently and significantly associated with unfavorable long-term outcomes in non-AF HT patients. Our study demonstrated that the hemostasis functions may be useful hematological markers for clinicians to recognize patients with a high risk of HT at an early stage and improve unfavorable long-term outcomes in non-AF patients. 


\section{Supplementary Information}

The online version contains supplementary material available at https://doi. org/10.1186/s12883-021-02065-3.

Additional file 1: Table S1. Baseline characteristics of AIS patients according to subcategorized group by AF

Additional file 2: Table S2. Baseline characteristics of AIS patients according to the subcategorized groups of HT

Additional file 3: Table S3. Multivariate logistic regression analysis of predictive factors for $\mathrm{HI}$ and $\mathrm{HT}$ in non-AF patients

\section{Abbreviations}

HT: Hemorrhagic transformation; AIS: acute ischemic stroke; AF: atrial fibrillation; PLT: platelet counts; MPV: mean platelet volume; FIB: fibrinogen; $\mathrm{Cl}$ : confidence interval; OR: odds ratio; CT: computerized tomography; MRI: magnetic resonance imaging; TIA: transient ischemic attack; DWI: diffusion-weighted imaging; CAD: coronary artery disease; NIHS S: National Institutes of Health Stroke Scale; PT: prothrombin time; INR: international normalized ratio; mRS: modified Rankin Scale; $\mathrm{ICH}$ : intracerebral hemorrhage

\section{Acknowledgements}

We thank the study participants and the clinical staff for their support and contribution to this project.

\section{Authors' contributions}

HC: Conceptualization, Data Curation, Formal analysis, and Writing an original draft. YC: Data Curation and Formal analysis. YZ: Data Curation and Formal analysis. YR: Data Curation and Formal analysis. CY: Data Curation and Formal analysis. QC: Data Curation and Formal analysis. HC: Data Curation and Formal analysis. XL: Data Curation and Formal analysis. GH: Conceptualization, Project administration, and Resources. JH: Funding acquisition, Resources, and Writing-review \& editing. The author(s) read and approved the final manuscript.

\section{Funding}

This work was funded by grants from the Projects of National Natura Science Foundation of China (No.81873799).

\section{Availability of data and materials}

The data supporting this study are available from the corresponding author for a reasonable request.

\section{Ethics approval and consent to participate}

This study was approved by the Institutional Review Board (IRB), the First Affiliated Hospital of Wenzhou Medical University, and was following the Declaration of Helsinki promulgated by the National Institute of Health. We didn't have informed consent for it was a retrospective study and the patient profile was anonymous. The acquisition of retrospective data was approved by the Ethics Committee of the First Affiliated Hospital of Wenzhou Medical University and the Neurology Department of the First Affiliated Hospital of Wenzhou Medical University.

\section{Consent for publication}

Not Applicable.

\section{Competing interests}

The authors declare no competing interests.

\section{Author details}

'Department of Neurology, The First Affiliated Hospital of Wenzhou Medical University, Wenzhou 325000, Zhejiang, China. ${ }^{2}$ School of Mental Health, Wenzhou Medical University, Wenzhou 325000, Zhejiang, China.
Received: 10 October 2020 Accepted: 19 January 2021

Published online: 26 January 2021

\section{References}

1. Li J, Zhang P, Wu S, Wang Y, Zhou J, Yi X, Wang C. Stroke-related complications in large hemisphere infarction: incidence and influence on unfavorable outcome. Ther Adv Neurol Disord. 2019;12:1756286419873264.

2. Gumbinger C, Gruschka P, Bottinger M, Heerlein K, Barrows R, Hacke W, Ringleb P. Improved prediction of poor outcome after thrombolysis using conservative definitions of symptomatic hemorrhage. Stroke. 2012;43(1): 240-2.

3. Guenego A, Lecler A, Raymond J, Sabben C, Khoury N, Premat K, Botta D, Boisseau W, Maier B, Ciccio G, et al. Hemorrhagic transformation after stroke: inter- and intrarater agreement. Eur J Neurol. 2019;26(3):476-82.

4. Rao NM, Levine SR, Gornbein JA, Saver JL. Defining clinically relevant cerebral hemorrhage after thrombolytic therapy for stroke: analysis of the National Institute of Neurological Disorders and Stroke tissue-type plasminogen activator trials. Stroke. 2014;45(9):2728-33.

5. Kaesmacher J, Kaesmacher M, Maegerlein C, Zimmer C, Gersing AS, Wunderlich S, Friedrich B, Boeckh-Behrens T, Kleine JF. Hemorrhagic Transformations after Thrombectomy: Risk Factors and Clinical Relevance. Cerebrovasc Dis (Basel, Switzerland). 2017:43(5-6):294-304.

6. Demirtas BS, Ocek L, Zorlu Y, Oztekin O. Factors associated with hemorrhagic transformation in infarctions involving the posterior circulation system. J Stroke Cerebrovasc Dis. 2019;28(8):2193-200.

7. Ge WQ, Chen J, Pan H, Chen F, Zhou CY. Analysis of risk factors increased hemorrhagic transformation after acute ischemic stroke. J Stroke Cerebrovasc Dis. 2018:27(12):3587-90.

8. Jiao Y, Li G, Xing Y, Nie D, Liu X. Influencing factors of hemorrhagic transformation in non-thrombolysis patients with cerebral infarction. Clin Neurol Neurosurg. 2019;181:68-72.

9. Zhang G, He M, Xu Y, Li X, Cai Z, Guo Z, Meng P, Ji N, He X, Pang L. Hemoglobin A1c predicts hemorrhagic transformation and poor outcomes after acute anterior stroke. Eur J Neurol. 2018;25(12):1432-e1122.

10. Nakano $Y$, Kondo $T$, Osanai $H$, Murase $Y$, Nakashima $Y$, Asano H, Ajioka M, Sakai $K$, Inden $Y$, Murohara T. Clinical usefulness of measuring prothrombin time and soluble fibrin levels in Japanese patients with atrial fibrillation receiving rivaroxaban. J Cardiol. 2015;65(3):185-90

11. Nguyen TN, Morel-Kopp MC, Pepperell D, Cumming RG, Hilmer SN, Ward $\mathrm{CM}$. The impact of frailty on coagulation and responses to warfarin in acute older hospitalised patients with atrial fibrillation: a pilot study. Aging Clin Exp Res. 2017;29(6):1129-38.

12. Tu HT, Campbell BC, Christensen S, Desmond PM, De Silva DA, Parsons MW Churilov L, Lansberg MG, Mlynash M, Olivot JM, et al. Worse stroke outcome in atrial fibrillation is explained by more severe hypoperfusion, infarct growth, and hemorrhagic transformation. Int J Stroke. 2015;10(4):534-40.

13. Pfeilschifter W, Spitzer D, Pfeilschifter J, Steinmetz H, Foerch C. Warfarin anticoagulation exacerbates the risk of hemorrhagic transformation after rtPA treatment in experimental stroke: therapeutic potential of PCC. PLoS One. 2011;6(10):e26087.

14. Altavilla R, Caso V, Bandini F, Agnelli G, Tsivgoulis G, Yaghi S, Furie KL, Tadi $P$, Becattini C, Zedde M, et al. Anticoagulation after stroke in patients with atrial fibrillation. Stroke. 2019;50(8):2093-100.

15. Nam KW, Kim TJ, Lee JS, Kwon HM, Lee YS, Ko SB, Yoon BW. High neutrophil-to-lymphocyte ratio predicts stroke-associated pneumonia. Stroke. 2018:49(8):1886-92.

16. Lang C, Seyfang L, Ferrari J, Gattringer T, Greisenegger S, Willeit K, Toell T, Krebs S, Brainin M, Kiechl S, et al. Do women with atrial fibrillation experience more severe strokes? Results from the Austrian stroke unit registry. Stroke. 2017;48(3):778-80.

17. Christersson C, Wallentin $L$, Andersson $U$, Alexander JH, Alings M, De Caterina R, Gersh BJ, Granger CB, Halvorsen S, Hanna M, et al. Effect of apixaban compared with warfarin on coagulation markers in atrial fibrillation. Heart. 2019;105(3):235-42.

18. Testa S, Paoletti O, Legnani C, Dellanoce C, Antonucci E, Cosmi B, Pengo V, Poli D, Morandini R, Testa R, et al. Low drug levels and thrombotic complications in high-risk atrial fibrillation patients treated with direct ora anticoagulants. J Thromb Haemost : JTH. 2018;16(5):842-8.

19. Paciaroni M, Agnelli G, Corea F, Ageno W, Alberti A, Lanari A, Caso V, Micheli S, Bertolani L, Venti M, et al. Early hemorrhagic transformation of 
brain infarction: rate, predictive factors, and influence on clinical outcome: results of a prospective multicenter study. Stroke. 2008;39(8):2249-56.

20. Hacke W, Kaste M, Fieschi C, von Kummer R, Davalos A, Meier D, Larrue V, Bluhmki E, Davis S, Donnan G, et al. Randomised double-blind placebocontrolled trial of thrombolytic therapy with intravenous alteplase in acute ischaemic stroke (ECASS II). Second European-Australasian Acute Stroke Study Investigators. Lancet (London, England). 1998;352(9136):1245-51.

21. Ornello R, Degan D, Tiseo C, Di Carmine C, Perciballi L, Pistoia F, Carolei A, Sacco S. Distribution and temporal trends from 1993 to 2015 of ischemic stroke subtypes: a systematic review and meta-analysis. Stroke. 2018;49(4):814-9.

22. Adams H, Leclerc J, Bluhmki E, Clarke W, Hansen M, Hacke W. Measuring outcomes as a function of baseline severity of ischemic stroke. Cerebrovasc Dis (Basel, Switzerland). 2004;18(2):124-9.

23. Uyttenboogaart M, Stewart RE, Vroomen PC, De Keyser J, Luijckx GJ. Optimizing cutoff scores for the Barthel index and the modified Rankin scale for defining outcome in acute stroke trials. Stroke. 2005;36(9):1984-7.

24. Zhang N, Wang C, Wang A, Bai Y, Zhou Y, Wang Y, Zhang T, Zhou J, Yu X, Sun $X$, et al. Time course of depression and one-year prognosis of patients with stroke in mainland China. CNS Neurosci Ther. 2012;18(6):475-81.

25. Putaala J, Haapaniemi E, Kaste M, Tatlisumak T. How does number of risk factors affect prognosis in young patients with ischemic stroke? Stroke. 2012;43(2):356-61.

26. Kelly P, Murphy S, Coveney S, Purroy F, Lemmens R, Tsivgoulis G, Price C. Anti-inflammatory approaches to ischaemic stroke prevention. J Neurol Neurosurg Psychiatry. 2018;89(2):211-8.

27. Andrade J, Mohr J, Lima F, Barros L, Nepomuceno C, Portela L, Silva G. Predictors of hemorrhagic transformation after acute ischemic stroke based on the experts' opinion. Arq Neuropsiquiatr. 2020;78(7):390-6.

28. Liu MS, Liao Y, Li GQ. Glomerular filtration rate is associated with hemorrhagic transformation in acute ischemic stroke patients without thrombolytic therapy. Chin Med J. 2018;131(14):1639-44.

29. Tan S, Wang D, Liu M, Zhang S, Wu B, Liu B. Frequency and predictors of spontaneous hemorrhagic transformation in ischemic stroke and its association with prognosis. J Neurol. 2014;261(5):905-12.

30. Vilanilam GK, Badi MK, Yarlagadda B, Okromelidze L. Hemorrhagic transformation after acute ischemic stroke in atrial fibrillation patients. J Stroke Cerebrovasc Dis. 2019:28(1):234.

31. Powers WJ, Rabinstein AA, Ackerson T, Adeoye OM, Bambakidis NC, Becker K, Biller J, Brown M, Demaerschalk BM, Hoh B, et al. 2018 guidelines for the early Management of Patients with Acute Ischemic Stroke: a guideline for healthcare professionals from the American Heart Association/American Stroke Association. Stroke. 2018;49(3):e46-e110.

32. Wang $R$, Zeng J, Wang F, Zhuang $X$, Chen $X$, Miao J. Risk factors of hemorrhagic transformation after intravenous thrombolysis with rt-PA in acute cerebral infarction. QJM. 2019;112(5):323-6.

33. Prodan Cl, Stoner JA, Cowan LD, Dale GL. Lower coated-platelet levels are associated with early hemorrhagic transformation in patients with nonlacunar brain infarction. J Thromb Haemost : JTH. 2010;8(6):1185-90.

34. Ho-Tin-Noé B, Demers M, Wagner D. How platelets safeguard vascular integrity. J Thromb Haemost : JTH. 2011:56-65.

35. Salas-Perdomo A, Miro-Mur F, Gallizioli M. Role of the S1P pathway and inhibition by fingolimod in preventing hemorrhagic transformation after stroke. Sci Rep. 2019;9(1):8309.

36. Martin JF, Trowbridge EA, Salmon G, Plumb J. The biological significance of platelet volume: its relationship to bleeding time, platelet thromboxane B2 production and megakaryocyte nuclear DNA concentration. Thromb Res. 1983:32(5):443-60

37. Vizioli L, Muscari S, Muscari A. The relationship of mean platelet volume with the risk and prognosis of cardiovascular diseases. Int J Clin Pract. 2009; 63(10):1509-15.

38. Bath PM, Butterworth RJ. Platelet size: measurement, physiology and vascular disease. Blood Coagul Fibrinolysis. 1996;7(2):157-61.

39. Staszewski J, Pogoda A, Data K, Walczak K, Nowocien M, Frankowska E, Stepien A. The mean platelet volume on admission predicts unfavorable stroke outcomes in patients treated with IV thrombolysis. Clin Interv Aging. 2019;14:493-503.

40. Xu X, Li C, Wan T, Gu X, Zhu W, Hao J, Bao H, Zuo L, Hu H, Li G. Risk factors for hemorrhagic transformation after intravenous thrombolysis in acute cerebral infarction: a retrospective single-center study. World neurosurg. 2017;101:155-60.
41. Huang GQ, Zeng YY, Cheng QQ, Cheng HR, Ruan YT, Yuan CX, Chen YB, He $\mathrm{WL}$, Chen HJ, He JC. Low triiodothyronine syndrome is associated with hemorrhagic transformation in patients with acute ischaemic stroke. Aging. 2019:11(16):6385-97.

42. Alvarez-Sabin J, Maisterra O, Santamarina E, Kase CS. Factors influencing haemorrhagic transformation in ischaemic stroke. Lancet Neurol. 2013;12(7): 689-705.

43. Luyendyk JP, Schoenecker JG, Flick MJ. The multifaceted role of fibrinogen in tissue injury and inflammation. Blood. 2019;133(6):511-20.

44. Ito A, Niizuma K, Shimizu H, Fujimura M, Hasumi K, Tominaga T. SMTP-7, a new thrombolytic agent, decreases hemorrhagic transformation after transient middle cerebral artery occlusion under warfarin anticoagulation in mice. Brain Res. 2014;1578:38-48.

45. Babu R, Bagley JH, Di C, Friedman AH, Adamson C. Thrombin and hemin as central factors in the mechanisms of intracerebral hemorrhage-induced secondary brain injury and as potential targets for intervention. Neurosurg Focus. 2012;32(4):E8.

46. Krenzlin H, Gresser E, Jussen D, Riede N, Taylor L, Vogelaar CF, Ringel F, Kempski O, Alessandri B. The Cerebral Thrombin System Is Activated after Intracerebral Hemorrhage and Contributes to Secondary Lesion Growth and Poor Neurological Outcome in C57BI/6 Mice. J Neurotrauma. 2020;37(12): $1481-90$.

47. Chen B, Friedman B, Whitney MA, Winkle JA, Lei IF, Olson ES, Cheng Q, Pereira B, Zhao L, Tsien RY, Lyden PD. Thrombin activity associated with neuronal damage during acute focal ischemia. J Neurosci. 2012;32(22): 7622-31.

\section{Publisher's Note}

Springer Nature remains neutral with regard to jurisdictional claims in published maps and institutional affiliations.

Ready to submit your research? Choose BMC and benefit from:

- fast, convenient online submission

- thorough peer review by experienced researchers in your field

- rapid publication on acceptance

- support for research data, including large and complex data types

- gold Open Access which fosters wider collaboration and increased citations

- maximum visibility for your research: over $100 \mathrm{M}$ website views per year

At $\mathrm{BMC}$, research is always in progress.

Learn more biomedcentral.com/submissions 